\title{
Philadelphia Chromosome In Acute Lymphoblastic Leukemia
}

\author{
Dina Adel Fouad phD ${ }^{1}$, Hasnaa A Abo_Elwafa phD ${ }^{2}$, Ahmed Allam $\mathrm{MD}^{2}$, Shereen Philip MD', \\ Nesma Mokhtar MSC ${ }^{2}$
}

Clinical Pathology Department Faculty of Medicine, Ain Shams University ${ }^{1}$ and Sohag University $^{2}$

\begin{abstract}
Background. Acute lymphoblastic leukemia (ALL) is a malignant disease of the bone marrow in which early lymphoid precursors proliferate and replace the normal hematopoietic cells of the marrow. Philadelphia chromosome (Ph)-positive ALL, a high-risk cytogenetic subset, accounts for $25-30 \%$ of adult ALL cases but occurs in less than 5\% of children. We aimed with this study to detect $\mathrm{Ph}$ chromosome in acute lymphoblastic leukemia patients, using (FISH), and to assess their relation with other standard prognostic factors and therapeutic response.

Patients and methods. This study was carried out on 39 newly diagnosed ALL patients. All patients were subjected to; History, clinical examination and Laboratory investigations, which included CBC (Complete Blood Count), P.BL.(Peripheral Blood) smear and BM(Bone Marrow) examination, immunophenotyping and Fluorescence in situ hybridization to detect $\mathrm{Ph}$ chromosome.

Results. This study was carried out on 39 newly diagnosed ALL patients show: Statistical analysis of patients' $t(9 ; 22)$ with other factors revealed significant association $(p<0.05)$ of $t(9 ; 22)$ with patients outcome, age >35 years, hepatosplenomegaly, absence of lymphadenopathy, TLC $\geq 50 \mathrm{X} 10^{9} / \mathrm{L}$, absolute P.Bl blasts $\geq 4.4 \mathrm{X} 10^{9} / \mathrm{L}$ and immunophenotyping.

Conclusion. $\mathrm{Ph}$ chromosome expression serve as a powerful prognostic marker in adulthood ALL, As ph +ve adult acute lymphoblastic leukemia has poor prognosis and can be used as prognostic indicators for therapeutic response.
\end{abstract}

\section{Introduction}

Acute lymphoblastic leukemia (ALL) is a malignant (clonal) disease of the bone marrow in which early lymphoid precursors proliferate and replace the normal hematopoietic cells of the marrow (1).

Adult and childhood ALL differ markedly in the prevalence of various cytogenetic abnormalities. $\mathrm{Ph}$ positive ALL, a high-risk cytogenetic subset, accounts for $25-30 \%$ of adult ALL cases but occurs in less than $5 \%$ of children. (2).

$\mathrm{Ph}$ chromosome results from a reciprocal translocation that fuses the Abelson tyrosine kinase (ABL1) from chromosome 9 to the breakpoint cluster region (BCR) on chromosome 22. The unique biology of $\mathrm{Ph}+\mathrm{ve}$ acute lymphoblastic leukemia (ALL) is attributable to the constitutive expression of oncoprotein BCR/ABL1 with tyrosine kinase activity. (3).

Fluorescence in situ hybridization technology represents an important advancement in cytogenetics. FISH is a marriage of classical cytogenetics and molecular technologies and has a large number of applications. FISH techniques have replaced special stains in many laboratories (4).

These powerful techniques allow us to detect and physically map on interphase nuclei, chromatin fibers, or metaphase chromosomes probes derived from single copy genes to repetitive DNA sequences. (5). 
Aim of the work: This work aims to detect $\mathrm{Ph}$ chromosome in acute lymphoblastic leukemia patients, using fluorescence in situ hybridization (FISH), and to assess their relation with other standard prognostic factors and therapeutic response.

Patients and methods: This study was carried out on 39 acute lymphoblastic leukemia (ALL) patients who were attending the hematology oncology clinics. All patients were subjected to the following: History, clinical examination and laboratory investigations, which included: CBC using LH750 (Beckman
Coulter), Examination of Leishman stained P.BL. , B.M.A and examination of Leishman stained smears. Immunophenotyping on BM or P.BL. samples, performed on EPICS XL Coulter Flow cytometer and Fluorescence in situ hybridization for detection of $\mathrm{t}(9 ; 22)(\mathrm{q} 34 ; \mathrm{q} 11)$

Statistical Analysis Methods : IBM SPSS statistics (V. 22.0, IBM Corp., USA, 2013) was used for data analysis. The probability of error at 0.05 was considered significant, while at 0.01 and 0.001 are highly significant.

\section{Results}

Clinical findings: The current study was carried out on 39 newly diagnosed adult ALL patients. Out of all patients; $24(61.5 \%)$ were males and $15(38.5 \%)$ were females with male to female ratio of (1.6:1). $19(48.7 \%)$ patients presented with hepatomegaly , 20 (51.3\%) patients presented with splenomegaly, $24(61.5 \%)$ patients presented with lymphadenopathy and $2(5.1 \%)$ patients presented with CNS infiltration.

Laboratory findings: 1 -Hemoglobin level $(\mathrm{Hb})$ ranged from 4.6 to $10.1 \mathrm{~g} / \mathrm{dl}$ with a mean value of $(7.35 \pm 1.6) \mathrm{g} / \mathrm{dl}$. 2-Total leucocytic count (TLC): ranged from 2.6 to $101 \times 109 / \mathrm{L}$ with a median value of $(51.8 \pm 30.2) \times 109 / \mathrm{L}$. 3-Platelets count: ranged from 33 to $128 \times 109 / \mathrm{L}$ with a mean value of $(80.5 \pm 26.7) \times 109 / \mathrm{L}$. 4-Absolute peripheral blood blast: ranged from 2 to $61 \times 109 / \mathrm{L}$ with a mean value of (31.5)x109/L. 5-B.M.E: According to WHO classification, The absolute BM blast ranged from 24 to $98 \times 10^{9} / \mathrm{L}$ with a mean value of $(66 \pm 21) \times 10^{9} / \mathrm{L}$. 6-Immunophenotyping (IPT): 35 of patients were expressing CD10. Among them CD13 or 33 were positive in 6 patients .

Fluorescence in Situ Hybridization Analysis:

Metaphase and/or interphase FISH analysis were successfully performed on 39 BM and/or P.BL. samples and revealed the following:

Structural aberrations: Positive results for $\mathrm{t}(9 ; 22)$ was encountered in $11(28.2 \%)$ patients, 11(q23) was detected in $2(5.1 \%)$ patients, $\mathrm{t}(1 ; 19)$ was detected in $1(2.5 \%)$ patient.

Results of ALL patients't(9;22) in relation to different prognostic factors: Showed significant association $(\mathrm{p}<0.05)$ of $\mathrm{ph}$ chromosome +ve cases with age $>35$ years, hepatosplenomegaly, absence of lymphadenopathy, TLC $\geq 50 \times 10^{9} / \mathrm{L}$, absolute P.B1 blasts $\geq 4.4 \times 10^{9} / \mathrm{L}$ and immunophenotyping. On the other hand, gender, CNS infilteration, $\mathrm{Hb}$ and platelet count showed non significant statistical difference $(\mathrm{p}>0.05)$ (Table 1). 
SOHAG MEDICAL JOURNAL

Vol. 21 No.3 october 2017

Table(1): Results of ALL patients't $(9 ; 22)$ in relation to different prognostic factors:

\begin{tabular}{|c|c|c|c|c|c|c|c|c|c|}
\hline \multirow{3}{*}{ 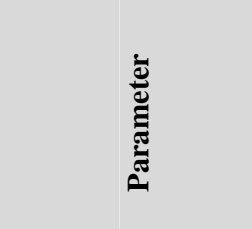 } & \multirow{3}{*}{ 旁 } & \multirow{3}{*}{$\dot{\mathbf{z}}$} & \multirow{3}{*}{$\Delta^{0}$} & \multicolumn{4}{|c|}{$\mathbf{t}(9 ; 22)($ total No.=11) } & \multirow{3}{*}{$a$} & \multirow{3}{*}{ 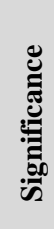 } \\
\hline & & & & \multicolumn{2}{|c|}{+ ve } & \multicolumn{2}{|c|}{-ve } & & \\
\hline & & & & $\dot{\mathbf{z}}$ & $a^{2}$ & $\dot{\mathbf{z}}$ & 8 & & \\
\hline Age(Years) & $\begin{array}{l}\geq 35 \\
<35\end{array}$ & 18 & $\begin{array}{l}46.2 \\
538\end{array}$ & 9 & $\begin{array}{l}81.8 \\
18 ?\end{array}$ & $\begin{array}{c}9 \\
19\end{array}$ & 32.1 & 0.005 & HS \\
\hline Sex & Male & 24 & 61.5 & 7 & 63.6 & 17 & 60.7 & 0.866 & NS \\
\hline Hepatomegaly & Yes & 19 & 48.7 & 11 & 100 & 8 & 28.6 & 0.000 & HS \\
\hline & $\begin{array}{l}\text { No } \\
\text { Yes }\end{array}$ & $\frac{20}{20}$ & $\frac{51.3}{513}$ & $\frac{0}{11}$ & $\frac{0}{100}$ & $\frac{20}{9}$ & $\begin{array}{l}11.4 \\
32.1\end{array}$ & & \\
\hline Splenomegaly & No & 19 & 48.7 & 0 & 0 & 19 & 67.9 & 0.000 & HS \\
\hline I & Yes & 24 & 61.5 & 1 & 9.1 & 23 & 82.1 & 0000 & WC \\
\hline Lymphadenopathy & No & 15 & 38.5 & 10 & 90.9 & 5 & 17.9 & 0.000 & $\mathrm{HS}$ \\
\hline CNS Infilteration & Yes & 2 & 5.1 & 1 & 9.1 & 1 & 3.6 & 0482 & NS \\
\hline CNS Infilteration & No & 37 & 94.9 & 10 & 90.9 & 27 & 96.4 & 0.482 & $\mathrm{NS}$ \\
\hline $\mathrm{Hh}$ & $<10 \mathrm{~g} / \mathrm{dl}$ & 36 & 92.3 & 9 & 81.8 & 27 & 96.4 & 0123 & NS \\
\hline $\mathrm{Hb}$ & $\geq 10 \mathrm{~g} / \mathrm{dl}$ & 3 & 7.7 & 2 & 18.2 & 1 & 3.6 & 0.123 & $\mathrm{NS}$ \\
\hline TI $C\left(\mathrm{x} 10^{9} / \mathrm{d}\right)$ & $<50$ & 26 & 66.7 & 3 & 27.3 & 23 & 82.1 & 0.001 & HS \\
\hline $1 L C(X 107 \mathrm{~L})$ & $\geq 50$ & 13 & 33.3 & 8 & 72.7 & 5 & 17.9 & 0.001 & $\mathrm{HS}$ \\
\hline Platelet & $<100$ & 33 & 84.6 & 11 & 100 & 22 & 78.6 & 0.005 & NS \\
\hline $\operatorname{count}\left(\times 10^{9} / \mathrm{L}\right)$ & $\geq 100$ & 6 & 15.4 & 0 & 0 & 6 & 21.4 & 0.095 & $\mathrm{NS}$ \\
\hline Ahsolute PB Blasts & $<4.4$ & 19 & 48.7 & 1 & 9.1 & 18 & 64.3 & 0007 & HS \\
\hline Absolute PB Blasts & $\geq 4.4$ & 20 & 51.3 & 10 & 90.9 & 10 & 35.7 & 0.002 & $\mathrm{HS}$ \\
\hline & CD10: & & & & & & & & \\
\hline & Positive & 35 & 89.7 & 11 & 100 & 24 & 85.7 & 0.314 & NS \\
\hline IPT & Negative & 4 & 10.3 & 0 & 0 & 4 & 14.3 & & \\
\hline & CD13/33: & 6 & 154 & 5 & 455 & 1 & 3.6 & & \\
\hline & Positive & 33 & 84.6 & 6 & 54.5 & 27 & 96.4 & 0.000 & HS \\
\hline
\end{tabular}

P: Prevelance HS: Highly Significant, S: Significant, NS: None Significant, Hb: hemoglobin, TLC: total leucocytic count, IPT; Immunophenotyping.

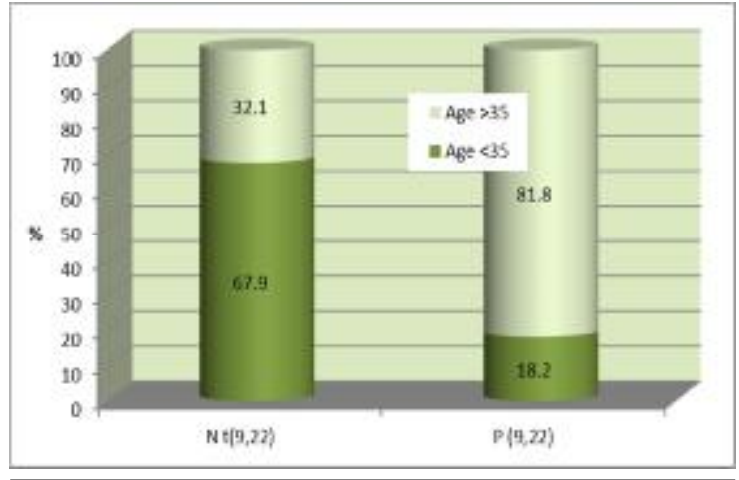

Figure (1): Bar chart of age in relation to ALL patients't $(9 ; 22)$.

$81.8 \%$ of patients with $\mathrm{t}(9 ; 22)$ had age $>35$ yrs old.

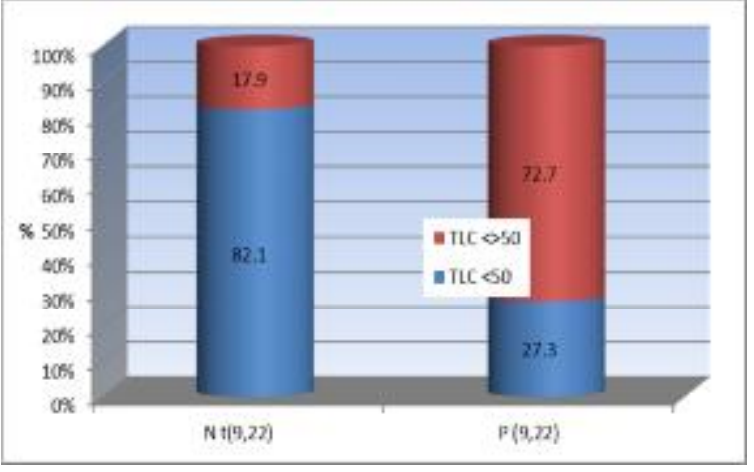

Figure (2): Bar chart of TLC in relation to ALL patients't $(9 ; 22)$.

$72.7 \%$ of patients with $\mathrm{t}(9 ; 22)$ had TLC $>50 \times 109 / \mathrm{L}$ 


\section{Discussion}

The current study was carried out on thirty nine diagnosed patients suffering from acute lymphoblastic leukemia.

In the present work ph chromosome present in 11 patients with a frequency of $28.2 \%$ (11/39 cases). This is in concordance with (Ghazavi F et al., 2015) who reported that ph chromosome is occurs with an incidence in adult $(30 \%)$ but slightly higher than (Noreen et al.,2012) who reported that $\mathrm{BCR} / \mathrm{ABL}$ fusion gene is occurs with an incidence $(20.3 \%)$.

Moreover MLL (11q23) gene rearrangements present in 2 patients with a frequency of $5.1 \%$ which lesser than (Schafer et al., 2015) who reported MLL gene rearrangement with $10 \%$ in adult ALL and $8 \%$ of pediatric ALL with about $80 \%$ of them in infants. the $t(1 ; 19)$ present in one patient with a frequency of $2.56 \%$ which is in concordance with (Al Ustwania et al., 2016) that reported $\mathrm{t}(1 ; 19) 3 \%$ in adult ALL.

According to $t(9 ; 22)$ in relation to different prognostic factors. It showed that most of ph +ve ALL patients were presented with age $>35$ years old so high significant relation $(\mathrm{p}=0.005)$ was detected between the patients age and $\mathrm{ph}$ +ve ALL patients. As regards clinical findings in this work, all of ph +ve ALL patients had hepatosplenomegaly with high significant relation $(\mathrm{p}=0.000)$ between them. While $9.1 \%$ of ph +ve ALL patients had lymphadenopathy with high significant, negative relation $(p=0.000)$ between lymphadenopathy and ph +ve ALL patients. But $9.1 \%$ had CNS infilteration with no significant association $(\mathrm{p}=0.482)$ to $\mathrm{ph}+\mathrm{ve}$, but these results differ from (Ilana de Franc et al.,2014) that showed no statistically significant differences between BCR-
ABL positive and negative patients in respect to the clinical variables.

As regards the haematological findings, There was high significant statistical association could be detected between $\mathrm{t}(9 ; 22)$ and $\mathrm{TLC} \geq 50 \times 10^{9} / \mathrm{L}$ with $(\mathrm{p}=0.001)$ and with absolute P.Bl blasts $\geq 4.4 \times 10^{9} / \mathrm{L}$ with $(\mathrm{p}=0.001)$ This finding is concordant with the previously published reports by (Cetin et al.,2012).

No significant statistical association could be detected between $t(9 ; 22)$ and CNS infilteration, $\mathrm{Hb}$ level $<10 \mathrm{~g} / \mathrm{dl}$, platelets $<100 \times 10^{9} / \mathrm{L}$ and CD10 . This finding is concordant with the previously published reports by (Cetin et al.,2012).

Immunophenotypic patterns of ph+ve ALL patients in this work including CD10 and aberrant expression of CD13 or 33, show no significant $(\mathrm{P}=0.314)$ statistical association was detected between $\mathrm{CD} 10$ and $\mathrm{t}(9 ; 22)$. Similary in, (Sanam et al.,2015) reported that CD10 expression had no statistical relationship with $t(9 ; 22)$. On the other hand, There was high negative significant association $(\mathrm{p}=0.000)$ was detected between $\mathrm{t}(9 ; 22)$ and CD13 or 33 positive expression.

There was high significant, negative correlation between outcome and positive ph chromosome $t(9 ; 22)$. among 11 cases with ph +ve only two cases had CR but nine cases had IR. these results are in agreement with those reported by

\section{( Aldoss et al.,2015)}

\section{Conclusion}

ph chromosome expression may serve as a powerful prognostic marker in adulthood ALL, As ph +ve adult acute lymphoblastic leukemia has poor prognosis. and can be used as prognostic indicators for therapeutic response. 


\section{References}

1- Jiang H (2010): The different signal patterns of two FISH probes in the FISH detection of Ph-positive leukemia and their clinical significance 2010 Apr;27(2):166-70. doi: $\quad 10.3760 / \mathrm{cma}$.j.issn.10039406.2010.02.011.

2- Ghazavi F, Tim L, Nadine VR, Bruce P, Frank S, Yves B, Pieter VV and Barbara DM. (2015): "Molecular basis and clinical significance of genetic aberrations in B-Cell precursor acute lymphoblastic leukemia." Experimental Hematology, vol. 43, no. 8, pp.640653., doi:10.1016/j.exphem.

3- Bachanova, Veronika (2017): "Philadelphia-positive Acute Lymphoblastic Leukemia: Do We Still Need Allogeneic Transplantation? Argument "Pro"." Clinical Lymphoma Myeloma and Leukemia 17 (2017): S10-15. Copyright (C) 2017 Elsevier Inc.

4- Gersen S, and Keagle M. (2013): The Principles of Clinical Cytogenetics (Third Edition ed., p. 561). New York: Springer Science Business Media New York.

5-Pita M, Orellana J, MartinezRodriguez P, Martinez-Ramirez A, Fernandez-Calvin B and Bella J (2014): In FISH methods in cytogenetic studies. In Functional Analysis of DNA and Chromatin (Methods in Molecular Biology); (first edition), Chapter (10); 1094:109-35, Springer Sceince+ Business Media, New York, USA.

6- Noreen S, Zafar I, Aamer A, Tashfeen A, Tahir N and Sultan A.(2012): Prognostically significant fusion oncogenes in Pakistani patients with adult acute lymphoblastic leukaemia and their association with disease biology and outcome. Asian Pacific J Cancer Prev 2012;13.7:3349-55.

7- Schafer Eric S.; Margolin, Judith; Poplack, David G. and Rabin, Karen R. (2015): . Molecular Genetics of Acute Lymphoblastic Leukemia, Molecular Basis of Cancer, 4th ed, vol. 26, 395-406.

8- Al Ustwania Omar, Neha Guptab, Hatoon Bakhribaha, Elizabeth Griffithsa, Eunice Wanga and Meir Wetzler (2016): Clinical updates in adult acute lymphoblastic leukemia, Critical Reviews in Oncology/Hematology 99; 189-199.

9- Ilana de France, Rui Milton P, Audrey Violeta M, Washington B, Fárida C and Raul A.,(2014) : "Frequency of p190 and p210 BCR-ABL rearrangements and survival in Brazilian adult patients with acute lymphoblastic leukemia." Fundac,ão de Hematologia e Hemoterapia de Pernambuco (HEMOPE), vol. 36, no. 5, 18 July 2014, pp. 351-355., doi:org/10.1016/j.bjhh.2014.07.016.

10- Cetin Z, Sezin Y, Ihsan K, Alphan K, Aysen T, Ozan S, Gulsun T, Guchan A, Demircan O, Volkan H, Mehmet AY, Levent U, Guven L, and Sibel B.(2012): "Aberrations of Chromosomes 9 and 22 in Acute Lymphoblastic Leukemia Cases Detected by ES-FluorescenceIn SituHybridization." Genetic Testing and Molecular Biomarkers, vol. 16, no. 5, pp. 318-323., doi:10.1089/gtmb.2011.0186.

11- Sanam Loghavi, Jeffery L. Kutok and Jeffrey L. Jorgensen. (2015): "BAcute Lymphoblastic Leukemia/Lymphoblastic Lymphoma ." American Journal of Clinical Pathology, vol. 144, no. 3, pp. 393410., 
doi:org/10.1309/AJCPAN7BH5DNY WZB.

12- Aldoss I, Tracey S, Vinod P, Joycelynne P and Stephen F (2015): "The prognostic significance of additional cytogenetic abnormalities in adults with Philadelphia chromosome positive acute lymphoblastic leukemia undergoing allogeneic stem cell transplant." Clinical Lymphoma Myeloma and Leukemia, vol.

15 , doi:10.1016/j.clml.2015.04.012. 